if it was so, this would be the longest latency period recorded. Moreover, unlike other cases occurring after surgery, ${ }^{5}$ no communication between the abscess and the previous field of surgery was demonstrated.

I wish to thank Mr J Spencer for his permission to publish this case.

A Aulaqi

$$
\begin{aligned}
& \text { Royal Postgraduate Medical } \\
& \begin{array}{l}
\text { Royal Post } \\
\text { School, }
\end{array} \\
& \text { Hammersmith Hospital, } \\
& \text { British Medical fournal, 1973, 1, } 365 \\
& \mathrm{R} \text {, et al, Australian and New Zealand } \\
& \text { Fournal of Surgery, 1975, 45, } 66 . \\
& \text { p 76. Phice et al, Medical Mycology, 2nd edn, } \\
& \text { p 76. Philadelphia, Lea and Febiger, } 1970 .
\end{aligned}
$$

\section{Treatment of acute paracetamol} poisoning

SIR,-Some of the statements in your leading article on the treatment of acute paracetamo poisoning (20 August, p 481) need qualification.

(1) Oral methionine has been recommended for the routine treatment of paracetamol overdosage by the poisons unit at Guy's Hospital for all cases reported since $1974 .{ }^{1}$ During 1975 they received 755 inquiries relating to paracetamol poisoning. Methionine treatment was recommended for all patients reputed to have taken more than $15 \mathrm{~g}$ of paracetamol (presenting within 10 hours of ingestion). The total number given methionine is not recorded, but the results from 36 treated cases admitted to the liver unit at King's College Hospital and to the Guy's Hospital intensive care unit have been reported by Crome et al. Thus, although the use of cysteamine has been more widely reported than that of methionine, the adoption of methionine as the recommended treatment of paracetamol poisoning in the south of England has led to its widespread use.

(2) Cysteine and methionine increase the amount of glutathione in the liver. However cysteamine does not, ${ }^{3}$ but appears to act mainly through inhibiting a cytochrome $\mathbf{P} 450$ mixed-function oxidase, thus reducing the oxidation of the paracetamol to the toxic intermediate.

(3) The relationship between hepatic damage and paracetamol half lives was originally reported by Prescott in $1971 .{ }^{4}$ How ever, a more accurate method of predicting possible hepatic damage based on the pharmacokinetics of paracetamol has been designed and reported. ${ }^{5}$ This method relies on rapid and accurate methods of blood level estimation of paracetamol, such as the blood paracetamol estimation kit," a technique for determining paracetamol levels on the ward not mentioned in your article.

(4) Cysteamine injection is not commercially available. Cysteamine is rapidly oxidised in solution to cystamine, but stable formulations of cysteamine injection have been developed. 9 Nevertheless, as these formulations have not been developed commercially the preparation requires a pharmacy with a sterile products production unit. (Prescott et $a l^{11}$ use a freeze-dried preparation prepared jointly by the pharmacy and the blood transfusion unit.) Thus cysteamine injection is not available in all hospitals. Methionine is readily available as powder or tablets and, as it can be given orally, poses no such pharmaceutical manufacturing problems.

The report of the Royal College of Physicians of London symposium on paracetamol and the liver ${ }^{11}$ lists the majority of these comments and gives the rationale behind the development of the treatments for acute paracetamol poisoning

Buckland Hospital,
Dover, Kent

F G R PRIOR

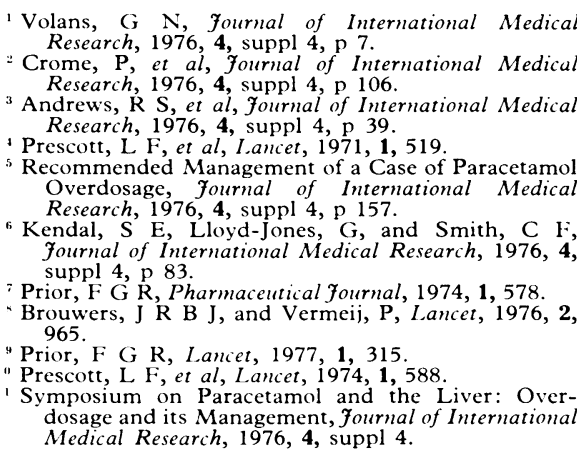

\section{Ventricular arrhythmias caused by} prenylamine

SIR,-With reference to the paper by $\mathrm{Dr} R$ Puritz and others (3 September, p 608) we would like to comment that their recommendations are in line with our own, which stress that prenylamine should be used with caution in patients taking certain other cardioactive drugs or drugs likely to induce hypokalaemia.

Our data sheet states that "prenylamine should be used with caution and in reduced dosage when combined with negative inotropic drugs-for example, $\beta$-adrenergic blocking agents, quinidine, etc, or drugs likely to produce hypokalaemia. Isolated reports indicate that on rare occasions such combinations are capable of producing paroxysmal ventricular tachycardia or fibrillation. Under such circumstances a marked increase in the duration of the Q-S or Q-T interval above the rateadjusted norm is an indication of the need to withdraw treatment with prenylamine."

W BOGIE Deputy Medical Director Hoechst UK Ltd,

Hounslow, Middlesex Pharmaceuticals Division

Skeletal scintigraphy in carcinoma of the breast

SIR,-Your leading article (3 September, $p$ 592) does well to draw attention to the need for a diagnostic imaging strategy in the evaluation of metastatic breast cancer.

Skeletal isotope scanning followed by conventional radiology of abnormal areas so demonstrated $^{1}$ is a realistic and economic approach. Patients with positive scans and negative radiographs then pose a problem. False-positive isotope scans of the spine may be due to degenerative joint disease of intervertebral or costovertebral origin or osteophyte formation. Plain radiographs may be unhelpful.

This dilemma is the subject of an ongoing study in this department" employing computed tomography (CT) with the EMI whole-body scanner. CT enables a precise analysis to be made of horizontal cross-sections 8 or $13 \mathrm{~mm}$ in thickness. Preliminary observations ${ }^{3}$ on 30 patients with breast cancer and positive isotope scans of the spine suggest that differentiation by CT between metastatic and degenerative joint disease even when the two are coincident in the spine is readily made. Lytic deposits unsuspected on conventional radiographs are demonstrable by CT.

It would seem that where whole-body CT is available it could be used in the "positive scan, negative radiograph" situation and certainly unnecessary bone biopsy avoided.

IAN ISHERWOOD

Department of Diagnostic Radiology,

University of Manchester

Roberts, J G, et al, Lancet, 1976, 1, 237.

Best, J J K B, et al. In preparation. April 1977.

\section{Hygiene in NHS hospitals}

SIR,-We have read the letters from $\mathrm{Dr}$ G A J Ayliffe and Mr B J Collins (2 July, p 48) and $\mathrm{Mr} \mathrm{G}$ Aston and $\mathrm{Dr} \mathrm{H}$ Gordon (27 August, p 579) with interest and would like to draw attention to the fact that for a considerable time Cuckfield and Crawley Health District has been aware of the importance of kitchen hygiene.

For a number of years past an open invitation has been extended to environmental health officers of the three local authorities within the health district boundary to visit, without prior notice, any of the hospital kitchens within the district for inspection purposes. After each visit a report is forwarded to district headquarters. A working party, consisting of the medical officer for environmental health, general administrator (support services), the local authority environmental health officer concerned, the unit catering manager, the unit administrator, and a representative of the works department, meets to discuss and where possible implement recommendations of the report. By this process not only is progress made towards achieving a high standard of kitchen hygiene but the local authority environmental health officer is aware of any financial constraints which might delay the early implementation of any of the recommendations. The essential rapport between officers of differing authorities and disciplines is also beneficially maintained.

BASIL RAEBURN

LIONEL F FORD

Cuckfield and Crawley Health District, West Sussex Area Health Authority,
Haywards Heath, Sussex

\section{Bell's palsy and herpes simplex}

SIR,-Herpes simplex virus (HSV) has been suggested, on theoretical grounds, as a possible cause of Bell's palsy. ${ }^{1}{ }^{2}$ I am able to find only one report of clinical HSV infection associated with Bell's palsy and that describes an HSV type II infection in a man with genital and oral ulcers immediately after the development of facial palsy. ${ }^{3}$ The present report describes a case of primary herpes stomatitis followed by mild Bell's palsy.

A European male aged 36 became unwell with a high temperature, multiple generalised mouth ulcers, and cervical lymphadenopathy. There was no suggestion of hand, foot, and mouth disease (more correctly, hand, foot, mouth, and bumps-a- 
daisy disease as a reminder to look for the usual buttock rash), nor were the ulcers palatal only. The clinical diagnosis at the time was primary herpes stomatitis. It was noted that his daughter might have had a similar episode two weeks previously. At follow-up two weeks later the patient had an obvious but mild hemifacial weakness of one week's duration. He had noted also slight numbness in the distribution of the maxillary branch of the trigeminal nerve but no other neurological deficit. Investigation at this time showed very high antibody titres to HSV and varicella-zoster $(\mathrm{V}-\mathrm{Z})$ but no elevation of the Coxsackie A16 titre. The Paul-Bunnell test was negative and there was no deficiency in the immune globulin profile. No specimen was taken from the mouth ulcers, which were by then healed. The facial weakness recovered in about a month.

That primary herpes simplex infections occur in adults is well recognised and the diagnosis is confirmed here by the high antibody titre. The $\mathrm{V}-\mathrm{Z}$ antibody titre was also elevated but this has been noted before in older patients with primary herpes simplex infections. ' The Bell's palsy may have been coincidental but it is probable that the HSV infection was causative. This would seem to add further support to the theory that HSV may be involved in the aetiology of Bell's palsy and general practitioners, who invariably manage. both HSV infections and Bell's palsy, are to be encouraged to search for more evidence of this association.

P GROUT

Conway, Gwynedd

McCormick, D P, Lancet, 1972, 1, 937 . Adour, $\mathrm{K} \mathrm{K}$, et al, Yournal of the American Medical
Association, 1975, 233, 527 .

${ }^{3}$ Lewis, B F, et al, Lancet, 1976, 1, 100.

Schmidt, $\mathrm{N} T$ T, et al, fournal of General Virology,
$1969,4,321$.

\section{Improving drug compliance after hospital discharge}

SIR,-Dr Elspeth Macdonald and her colleagues (3 September, p 618) would no doubt care to hear of the Swedish Dosett. It consists of 28 small compartments with transparent sliding panels, days of the week being marked across the top and four different times down the side. Drugs can be put out for a week and patients can see at a glance whether the dose has been taken or not. It is obtainable from E H Farma, Box 12171, S-102 25 Stockholm 12, Sweden.

St David's Hospital,

A R KEMP

Carmarthen

\section{The urethral syndrome}

SIR,-Your leading article (3 September, p 593), in dividing women suffering from recurrent frequency and dysuria into those with bacteriuria and those with a sterile urine, overlooks a third group who have asymptomatic bacteriuria and coincidentally acquire symptoms not caused by bacteriuria. Probably most of those whose symptoms last less than 24 hours and are found to have bacteriuria are in this group. They are not helped by antimicrobial therapy or measures intended to prevent infection.

The paper cited ${ }^{1}$ alleging benefit from internal urethrotomy was followed by a brief report $^{2}$ of a smaller but otherwise identical series of my own in which the patients were examined by cystoscopy and treated only by reassurance of the absence of serious disease and by simple commonsense advice. The proportions of those patients who had no symptoms who were definitely improved at followup after a minimum of two years were almost identical in the two series, allowing the comment, "Nothing works better than internal urethrotomy."

However, you are right to advocate thorough investigation for these patients, but this is mainly because such investigation allows the patient to be reassured that serious disease is not present. Fear of urogenital disease is, in my experience, a very important factor in exacerbating or maintaining this troublesome syndrome.

North Ormesby Hospital,

Middlesbrough, Clevelan

Farrar, D J, Green, $\mathrm{N} A$, and Ashken, $M \mathrm{R} \mathrm{H}$, British fournal of Urology, 1973, 45, 610. Hole, R, British fournal of Urology, 1973, 45, 615.

SIR,-Your comprehensive review of the urethral syndrome (3 September, p 593) prompts me to ask if any share my belief that the condition occurs in males as well as in females.

W FOWLER

\section{VD Department,}

Birmingham

\section{Helping mothers to love their babies}

SIR,-Your leading article on mothers and babies (3 September, p 595) is welcome. But why should the baby only "be shown briefly to the mother immediately after birth" and then be removed while the third stage of labour is completed? As a medical student in Glasgow 20 years ago I was taught that the baby should be put to the mother's breast immediately after birth and that the reflex contraction of the uterus resulting from the attempts to suckle of a healthy baby will expel the placenta and any blood clots, so speeding up the third stage without need for interference by third parties.

The idea that a mother needs to "rest" after delivery and that to achieve this she must be separated from her infant is probably responsible for many failures to establish breastfeeding. Lip-service is paid to the idea of breast-feeding, but if babies are taken away and given bottles they do not suck hard enough to establish a good flow of breast milk and the mother decides that she does not have enough milk for her baby and gives up. Normal babies should be allowed to sleep beside their mothers and they and their mothers should never see a feeding bottle. Then mothers and others might discover that breast-feeding really is possible, pleasureable, and economic and helps in the involution of the uterus - all of which seems obvious in communities where bottle-feeding has not yet been introduced.

For breast-feeding to continue successfully working mothers should be allowed and encouraged to take their babies to work with them. In most occupations this should be possible, and a contented baby will rarely make a disturbance if given a cuddle and a suck at reasonable intervals and, preferably, parked where it can see its mother. For this to happen probably requires a change in social attitude to make it acceptable for a mother to feed her infant in public, as it is among most of the population of the world. It is ironic that we seem to regard sexually provocative dress, or undress, by nubile girls as acceptable but the putting of her baby to the breast in public by a mother as indecent (though permissible in mediaeval paintings of the Virgin and Child). Breast is best!

Department of Tropica

Community Health School of Tropical Medicine,
Liverpool

\section{Carbon dioxide-dependent dwarf staphylococcus}

SIR,-Hale, ${ }^{1}$ in 1951 , was the first to record the isolation from an abscess of a dwarfcolony Staphylococcus aureus which was dependent on carbon dioxide for characteristic growth. Dwarf variants of a number of phage types, with similar requirements for $\mathrm{CO}_{2 .}$, were then reported from several laboratories, $=$ is isolated from patients who had received antibiotic treatment. We studied strains; isolated from a stye to which topical penicillin had been applied, from an untreated palmar abscess in a household contact, and from the nasopharynx of the patients concerned. On aerobic culture plates there grew only minute unpigmented colonies which were coagulaseand catalase-negative and thus "unrecognisable" as $S$ aureus. However, parallel cultures at $37 \mathrm{C}$ on plates containing $0.3 \%$ sodium bicarbonate as a $\mathrm{CO}$, source or incubated in jars with $1-10 \%$ of $\mathrm{CO}_{2}$ grew normally. It was found that coagulase, catalase, and pigment production varied with colony size, which was measurably $\mathrm{CO}_{2}$-dependent. These strains grew better at $30 \mathrm{C}$ than at $37 \mathrm{C}$ in air but in $\mathrm{CO}$, they grew best at $37 \mathrm{C}$. As has been indicated in your columns recently (Dr M Rahman, 30 July, p 319; Dr A Beck and $\mathrm{Mr}$ G Hounsome, 27 August, p 582), it can be important clinically that such atypical strains of $S$ aureus are recognised.

MAIR THOMAS

Elizabeth Garrett Anderson Hospital,

London NW

Hale, J H, British fournal of Experimental Pathology, $1951,32,307$.

Sherris, J C, fournal of Clinical Pathology, 1952, 5, 534.

ise, R I, and Spink, W W, fournal of Clinical Trvestigation, 1954, 33, 1611.

(9) Pathology, 1955, 8, 284 .

\section{Koch or Henle?}

SIR,-In a review of a book on viral infections edited by Alfred S Evans (3 September, p 630), Professor A P Waterson says that Jakob Henle formulated Koch's postulates "several years before Koch himself did" and that Evans prefers to speak of "the Henle-Koch postulates." This is one of the medicohistorical myths that continue to be repeated by authors who do not consult primary sources.

The original authors of this particular myth were Fildes and McIntosh ${ }^{1}$ who, 58 years ago, claimed: "These are not Koch's postulates, but Henle's." Their claim was made in a paper of 24 pages purporting to prove by the application of Koch's postulates that the influenza pathogen was not a "filter-passer" but "Bacillus influenzae." In fact, all that Henle said was that if living animalcules or distinct plants were found in contagious materials they 